\title{
SYSTEMIC TRANSPLANTATION OF BONE MARROW MONONUCLEAR CELLS PROMOTES AXONAL REGENERATION AND ANALGESIA IN A MODEL OF WALLERIAN DEGENERATION
}

Vanina Usach $\mathrm{PhD}^{1}$, Mariana Malet MD², Margarita López Tech ${ }^{3}$, Lucía Lavalle MD¹, Gonzalo Piñero Biochem ${ }^{1}$, María Saccoliti MD ${ }^{4}$, Alicia Cueto $\mathrm{MD}^{5}$, Pablo Brumovsky MD, $\mathrm{PhD}^{2}$, Alicia Brusco $\mathrm{PhD}^{3}$ and Patricia Setton-Avruj $\mathrm{PhD}^{1} *$

${ }^{1}$ Departamento de Química Biológica, Facultad de Farmacia y Bíoquímica, Universidad de Buenos Aires. Instituto de Química y Físicoquímica Biológica (IQUIFIB), UBA-CONICET

${ }^{2}$ Instituto de Investigaciones en Medicina Traslacional (IIMT), Universidad Austral-CONICET, Facultad de Ciencias Biomédicas, Universidad Austral, Buenos Aires, Argentina

${ }^{3}$ Instituto de Biología Celular y Neurociencias (IBCN), UBA-CONICET, Argentina

${ }^{4}$ Servicio de Anatomía Patológica Hospital Durand, Laboratorio de Enfermedades Neuromusculares Dra Taratuto

${ }^{5}$ Servicio de Neurología, Hospital Español de Buenos Aires. Argentina

* Corresponding author: phone $+541149648287 *$ fax $+541149625457 *$ e-mail address setton@qb.ffyb.uba.ar (P Setton-Avruj) 


\section{AUTHORSHIP PAGE}

-Vanina Usach, Lucía Lavalle, Gonzalo Piñero and Patricia Setton-Avruj were responsible for experimental model design and animal and sample preparation for all the protocols applied in the manuscript. They were also in charge of BMMC isolation, characterization and transplant. Besides, they performed the immunofluorescence analysis as well as the Western blot experiments and the quantification of most results obtained in experimental procedures.

Funding: University of Buenos Aires (UBACYT 20020100101017), CONICET (PIP 830 and PIP 567)

- Margarita López is an electronic microscopy technician in charge of sample preparation for electron and optical microscopy.

-María Saccoliti and Alicia Brusco participated in image analysis of semi-thin sections (by light microscopy) and ultra-thin sections (by electron microscopy).

-Alicia Cueto performed the electrophysiological studies

-Mariana Malet and Pablo Brumovsky performed mechanical paw withdrawal threshold behavioral test and subsequent result analysis.

Funding: Fondo para la Investigación Científica y Tecnológica (FONCyT; PICT 296) and Austral University.

Authors declare no conflict of interest 


\author{
ABBREVIATIONS PAGE \\ BMMC, bone marrow mononuclear cells \\ BMSC, bone marrow stromal cells \\ CMAP, compound muscle action potential \\ DPI, days post injury \\ FCS, fetal calf serum
}

IASP, International Association for the Study of Pain

IOD, integrated optical density

IR, immunoreactivity

MBP, myelin basic protein

PBS, phosphate-buffered saline

PVDF, polyvinyl difluoride membranes

RT, room temperature

SC, Schwann cells

WD, Wallerian degeneration 


\begin{abstract}
BACKGROUND: Reinnervation timing after nerve injury is critical for favorable axonal regeneration, remyelination and clinical improvement. Considering bone marrow mononuclear cells (BMMC) are easily obtained and readily available for transplant, this work analyzed the effect of BMMC systemic administration on nerve repair and pain behavior.
\end{abstract}

METHODS: Adult rats with sciatic nerve crush were immediately and systemically injected BMMC through the caudal artery. Nontreated, sham and naïve rats were also included. Histological, immunohistochemical, biochemical, functional and behavioral analyses were performed in nerves harvested from each group at different survival times.

RESULTS: Axons in BMMC-treated rats exhibited a more conserved morphological appearance than those in nontreated rats, as observed at different survival times both in semi-thin sections and ultrastructural analysis. BMMC-treated rats also showed a reduction in major myelin protein immunoreactive clusters 7 and 14 days post injury (DPI), as compared to nontreated rats. Electrophysiological analysis showed BMMC treatment to slightly improve the amplitude of compound muscle action potential (CMAP) starting at 14 DPI. Finally, mechanical withdrawal threshold revealed a full preventive action against transient mechanical hypersensitivity in BMMC-treated rats.

CONCLUSIONS: These data demonstrate the efficiency of BMMC, systemically and noninvasively transplanted, in correcting morphological, functional and behavioral alterations resulting from peripheral nerve injury. 


\section{INTRODUCTION}

Traumatic injury of peripheral nerves has a high incidence worldwide and is associated with partial or total functional loss of the affected limb and disabling neuropathic pain. Of relevance, reinnervation timing and the mechanisms underlying efficient regeneration become critical for favorable clinical evolution ${ }^{1}$.

Wallerian Degeneration (WD) is a pathophysiological process characterized by loss of axonSchwann cell (SC) contact followed by SC proliferation and myelin breakdown, essential steps for axonal regeneration and remyelination after nerve injury ${ }^{2}$. Numerous experiments have shown that SC transplantation promotes remyelination and enhances nerve conduction ${ }^{3,4}$, although drawbacks in its therapeutic application include the use of a healthy nerve and a significantly time-consuming culture procedure to obtain enough cells for transplantation. Currently, most efforts in stem cell-based therapies are directed toward characterizing a cell type which, in addition to driving remyelination, is multipotent and simple to obtain, can proliferate in vitro and is easily integrated in the host tissue. The cell types most commonly evaluated for the stimulation of nerve regeneration in different experimental models include bone marrow stromal cells $(\mathrm{BMSC})^{5}$, olfactory ensheathing cells ${ }^{6,7}$, endothelial precursors ${ }^{8}$, adipocyte-derived stem cells $^{9,10,11}$, dental-pulp-derived stem cells ${ }^{12}$ and skin-derived stem cells ${ }^{13}$.

Recently, bone marrow mononuclear cells $(\mathrm{BMMC})^{14,15}$ have emerged as a suitable option, as culture is not required and phenotypic rearrangements can be hence avoided ${ }^{16}$. BMMC represent a heterogeneous population including BMSC, hematopoietic stem cells ${ }^{17,18}$, hematopoietic ${ }^{18}$ and endothelial cell precursors ${ }^{19}$ and produce numerous cytokines and trophic factors promoting 
recovery in various types of tissue injury ${ }^{19,20,21}$. BMMC have been shown to differentiate into hepatocytes in animal models of hepatic damage ${ }^{22}$, whereas, in response to heart infarct, they either become miocytes or contribute to a reduction in inflammation ${ }^{23,24}$. BMMC also promote angiogenesis, neuroprotection and neuroregeneration, as observed in rodent models of central ${ }^{25}$, 26, 27 and peripheral ${ }^{28}$ nervous system injury.

We have previously shown that BMMC migrate, either spontaneously or after transplant, exclusively to the ipsilateral nerve in both irreversible (nerve ligation ${ }^{29}$ ) and reversible (sciatic nerve crush $^{30}$ ) models of WD; in the latter, BMMC were also shown to colocalize with axonal and SC markers ${ }^{30}$. In this context, the present work evaluated systemic transplant as a noninvasive method of BMMC administration and its impact on regeneration, nerve function recovery and pain modulation in rats with sciatic nerve crush.

\section{MATERIALS AND METHODS}

\section{Animals}

Adult Wistar rats were kept in standard conditions with food and water ad libitum on a 12-h day/night cycle. Experimental procedures were performed following the guidelines of Comité de Bioética at Facultad de Farmacia y Bioquímica, Universidad de Buenos Aires, and in accordance with the NIH Guide for the Care and Use of Laboratory Animals and EU Directive 2010/63/EU for animal experiments of the European Commission. Pain behavior analysis was conducted following the Society for Neuroscience and the International Association for the Study of Pain (IASP) guidelines for the use of animals in research, and approved by Comité de Ética at Instituto de Investigaciones en Medicina Traslacional (IIMT). 
For each experimental group and survival time, 5 animals were used for immunohistochemical and Western blot analyses, 3 animals for electron and optical microscopy analyses, 6 animals for electrophysiological studies and 11 animals for pain behavior analysis. A matching number of naïve animals was used for methodological studies, with the exception of pain behavior analysis.

\section{Sciatic nerve crush}

Surgery was performed as previously described ${ }^{30}$. Briefly, rats (70 days old, $270-300 \mathrm{~g}$ body weight) were anesthetized with ketamine (75 mg/kg i.p.) and xylazine (10 mg/kg i.p.) and their right sciatic nerves were exposed and crushed for 8 seconds at mid-thigh level with jeweler's forceps.

Animals were then divided into a nontreated (sciatic nerve crush plus saline solution injection) and a BMMC-treated (sciatic nerve crush plus BMMC injection) group and sacrificed at different days postinjury (DPI). For pain behavior analysis, a sham group (sciatic nerve exposed but left intact) was also included. At different DPI, the proximal, crush and distal areas in the ipsilateral nerve and the contralateral nerve were carefully identified, dissected out and used for experiments.

\section{BMMC isolation}

Femurs and tibias from adult Wistar rats weighing 300-400 g were dissected. Bone marrow was extruded with $\alpha$-MEM $+10 \%$ fetal calf serum (FCS; Natocor, Argentina) and the aspirate 
centrifuged through a Ficoll-Paque Plus $(1.077 \mathrm{~g} / \mathrm{ml})$ density gradient, as previously described ${ }^{29,}$ ${ }^{30}$. The interface containing the mononuclear cell fraction was used for further experiments.

\section{BMMC characterization}

Flow cytometry

Freshly isolated BMMC were washed in phosphate-buffered saline (PBS) supplemented with $1 \%$ FCS and then incubated with anti-CD34, a marker of progenitor cells (1/25, goat polyclonal IgG, Santa Cruz Biotechnology, Inc.), anti-CD90, a marker of multipotent cells and fibroblasts (1/25, mouse monoclonal IgG, clone OX-7, Chemicon Int), anti-CD45, a pan-hematopoietic marker (1/200, mouse monoclonal IgG, clone MRC OX-1 Chemicon Int), anti-CD11b, a myelinomonocytic marker (1/200, mouse monoclonal IgG, clone OX-42 Chemicon Int), FITC anti-CD3, a T lymphocyte marker (mouse monoclonal IgG clone G4.18, BD), anti-CD105, a MSC marker (1/25, rabbit polyclonal IgG, Bioss), anti-rat myelin basic protein (MBP, generously donated by Dr. Campagnoni, UCLA Neuroscience Research Building Department of Psychiatry and Biobehavioral Sciences. LA, USA; 1/25, IgG rabbit polyclonal), anti-rat $\mathrm{p} 75^{\mathrm{NTR}}$, a nonmyelinated and immature SC marker (1/200, rabbit polyclonal $\mathrm{IgG}$, Abcam), and antiS100ß, a SC marker (1/25, rabbit polyclonal IgG, Santa Cruz Biotechnology, Inc.) for 1 hour at room temperature (RT). For macrophage lineage marker CD68 (1/50, mouse monoclonal IgG clone ED1, Serotec.), prior to incubation with the antibody, cells were fixed in $0.01 \%$ paraformaldehyde for 10 minutes and then permeabilized with $0.5 \%$ PBS-Tween 20 for 15 minutes. After several washes, cells were incubated with Cy3- or Cy2-conjugated secondary antibodies (Jackson ImmunoResearch) for 1 hour at RT in the dark. Cells were washed again and 
analyzed with a Becton-Dickinson FACScalibur flow cytometer (San Jose, CA, USA). BMMC autofluorescence and nonspecific secondary antibody binding were used as controls.

\section{RNA preparation and RT-PCR}

Total RNA was extracted from BMMC using RNeasy Mini Kit, according to the manufacturer's instructions. RT-PCR was performed as previously described ${ }^{31}$. Primer sequences used are described in Table 1.

\section{Injection of freshly isolated BMMC}

Transplant of BMMC was done as previously described ${ }^{29}$. Briefly, BMMC-treated rats were transplanted $15 \times 10^{6}$ cells through the caudal artery immediately after sciatic nerve crush. A group of animals were transplanted BMMC labeled with cell tracker orange CMTMR (5-(and 6)(((4-chloromethyl)benzoyl)amino)tetramethyl-rhodamine). Non-treated animals were injected saline solution.

\section{Preparation of tissue sections and immunohistochemistry}

After 7 or 14 DPI, animals were sacrificed and sciatic nerves prepared for immunohistochemistry as described previously ${ }^{29,} 30$. Anti-rat MBP (1/400, IgG rabbit polyclonal), conditioned medium from the RT-97 hybridoma cell line (against NF-h, axonal marker, 1:10 IgG mouse, a kind gift of Dr. P. Monje. The Miami Project to Cure Paralysis. Miami, USA), anti-rat $\mathrm{P}_{0}$ (myelin marker, 1:500, IgG rabbit polyclonal, a kind gift of Dr. O. Bizzozero. University of New Mexico Health Sciences Center, Albuquerque, NM, USA) and anti-rat $\mathrm{p} 75^{\mathrm{NTR}}(1 / 200$, rabbit polyclonal IgG, Abcam) were used. Goat anti-rabbit Cy3 or donkey anti-mouse secondary antibodies (1/200) 
plus Höechst $32258(2 \mu \mathrm{g} / \mathrm{ml}$, Sigma Chem Co) were used accordingly. Analysis was performed using an Olympus FV1000 confocal microscope and an Olympus BX100 epifluorescence microscope.

\section{Western blot of BMMC and tissue proteins}

For tissue protein extraction, the proximal and distal areas and the contralateral nerve were dissected at different DPI and tissue was homogenized in $0.32 \mathrm{M}$ sucrose containing protease inhibitors. Protein quantification was done through Bradford's method ${ }^{32}$.

Proteins were electrophoresed on $16 \%$ SDS-PAGE and then transferred onto polyvinyl difluoride (PVDF) membranes for immunoblotting. Non-specific protein binding sites were blocked with $5 \%$ non-fat dry milk in $0.1 \%$ PBS-Tween20. Anti-rat MBP (1/3000, IgG rabbit polyclonal) was used and peroxidase-conjugated goat anti-rabbit (1/10000) antibody was used accordingly (Jackson Immuno Research). Immunocomplexes were revealed using diaminobenzidine.

\section{Electron and optical microscopy analysis}

Three, 7, 14 and 21 DPI, animals were anesthetized and perfused with 4\% paraformaldehyde plus $2.5 \%$ glutaraldehyde in $0.1 \mathrm{M}$ phosphate buffer $\mathrm{pH} 7.4$. The proximal, crush and distal area of the ipsilateral nerve and the contralateral sciatic nerve were removed and tissue prepared as previously described $^{33}$.

Freshly isolated BMMC were processed in the same way for morphological analyses. 
Semi-thin tissue sections were mounted onto glass slides and dyed with $0.5 \%$ toluidine blue in sodium carbonate $2.5 \%(\mathrm{w} / \mathrm{v})$.

Ultra-thin sections were collected on 300 mesh copper grids, dyed with $2 \%$ (w/v) aqueous uranyl, stained with Reynolds solution and later analyzed in a Zeiss EM 109T electron microscope. Photographs were obtained using Kodak 5301 films and an Epson Perfection V500 Photo scanner or a GAETA digital camera.

\section{Electrophysiological studies}

Electrophysiological studies were performed in both experimental groups 3, 7, 14, 21 and 60 DPI. In rats under anesthesia, and maintaining body temperature at $37^{\circ} \mathrm{C}$, nerve measurements were practiced by means of a portable electromyography instrument (Cadwell Wedge Sierra II, Cadwell Labs, Inc., Kennewick, WA, USA). Recording and ground electrodes were placed in the soleus muscle and the tail, respectively. The ipsilateral sciatic nerve was exposed and the proximal and distal areas were electrically stimulated. The same procedure was carried out in contralateral and naïve nerves. Stimulus intensity was $30 \mathrm{~mA}$ and a slight twitching of the limb was observed in all rats. The distal latency and the amplitude of the compound muscle action potential (CMAP) were recorded.

\section{Mechanical withdrawal threshold}

Hind-paw mechanical threshold was evaluated by using the Von Frey method as previously described $^{34,35}$. The withdrawal threshold was taken as the force needed to induce paw withdrawal in at least 2 out of 3 consecutive stimuli. A paw withdrawal reflex obtained with $6 \mathrm{~g}$ 
force or less was considered allodynia (pain-like response to a stimulus that does not normally evoke pain, IASP).

\section{Quantitative analysis}

All data were analyzed and quantified by experimenters who were blind to the experimental design. Briefly, microscopy images were analyzed using Image Pro Plus software (version 5.1). For semi-thin sections, the total number of axons $/ 100 \mu \mathrm{m}^{2}$ was calculated in 30 randomly selected fields. In ultra-thin sections, the number of myelin sheaths/100 nm was calculated, in addition to g-ratio (axon diameter/axon diameter including myelin sheath). The quantitative analysis of Western blot studies was performed using Gel Pro Analyzer. For each protein, the ratio of IOD band was calculated to total protein content in each line, as measured through Coomassie blue.

\section{Statistical analysis}

Parametric statistics studies were performed between experimental groups by applying ANOVA, followed either by Dunnett's or Tukey's test.

Nonparametric statistics was employed to analyze effects on pain behavior. Comparison between contralateral and ipsilateral hind-paw withdrawal thresholds was carried out by applying the Wilcoxon matched pairs test. Treatment effects at each DPI were analyzed using the KruskalWallis rank sum test. When appropriate, comparisons among groups were conducted with Dunn's multiple comparison post hoc test.

In all cases significance was stated at $\mathrm{p}<0.05$. 


\section{RESULTS}

\section{BMMC characterization previous to transplant}

Three different phenotypes were identified by microscopic observation, revealing a heterogeneous population (Fig. 1A). RT-PCR analyses showed isolated BMMC to express CD34, CD90 and S100ß mRNAs (Fig. 1B), but not p75 ${ }^{\mathrm{NTR}}$, GFAP, MBP or $\mathrm{P}_{0}$ mRNAs (data not shown). Flow cytometry analyses using FSC/SSC and CD45/SSC gate revealed that purification was effective in enriching the percentage of mononuclear cells (Fig $1 \mathrm{C}_{1}$, region $\mathrm{C}, \mathrm{D}$ and $\mathrm{E}$ ) and reducing the number of other cell types such as granulocytes (Fig. $1 \mathrm{C}_{1}$, region $\mathrm{A}$ ) and erythroid precursors (Fig. $1 \mathrm{C}_{1}$,region $\left.\mathrm{B}\right)^{36}$ (Fig. $1 \mathrm{C}_{1}$ ). Two subpopulations were found in the BMMC fraction, 1 with low and 1 with high CD45 expression (Fig. $1 \mathrm{C}_{2}$ ). Analysis of different cell markers revealed the presence of a small proportion of $\mathrm{CD} 45^{\text {low }} / \mathrm{CD} 34^{+}$cells $(2.3 \pm 0.78 \%$, Fig. $1 \mathrm{C}_{3}$ and $\left.1 \mathrm{C}_{4}\right)$, a small proportion of $\mathrm{CD} 45^{\text {low }} / \mathrm{CD} 105^{+}$cells $\left(2.75 \pm 0.16 \%\right.$, Fig. $1 \mathrm{C}_{3}$ and $\left.1 \mathrm{C}_{4}\right)$, and a large proportion of $\mathrm{CD} 45^{+} / \mathrm{CD} 90^{+}$cells $\left(34.1 \pm 2.2 \%\right.$, Fig. $1 \mathrm{C}_{3}$ and $\left.1 \mathrm{C}_{4}\right)$. Some $\mathrm{T}$ lymphocytes were also found $\left(\mathrm{CD} 45^{\text {low }} / \mathrm{CD}^{+} ; 9,52 \%\right)$, and a higher percentage of $\mathrm{CD} 45^{\text {high }}$ cells was observed to express CD68 and CD11b with similar pattern and levels (Fig. $1 \mathrm{C}_{3}$ and $1 \mathrm{C}_{4}$ ). In terms of SC markers, barely detectable levels of $\mathrm{p} 75^{\mathrm{NTR}}, \mathrm{S} 100 \beta$ and MBP were measured in BMMC (Fig. $1 \mathrm{C}_{3}$ and $1 \mathrm{C}_{4}$ ). As expected, the erythroid precursor region was negative for all the markers analyzed, while remaining granulocytes were all $\mathrm{CD}_{11} \mathrm{~b}^{+}$and weakly $\mathrm{CD}^{+} 8^{+}$(data not shown).

BMMC dyed with CMTMR cell tracker (Fig. $1 \mathrm{D}_{1}$ ) were used to confirm migration exclusively to the ipsilateral nerve $\left(\right.$ Fig. $\left.1 \mathrm{D}_{2}\right)$ as previously described ${ }^{30}$. Microscopic analysis of semi-thin sections was used to evaluate nerve morphology. Naïve animals exhibited intact axons, SC and 
fibroblasts (Fig. 1E). In contrast, distal areas showed irregular axons with myelin and axon debris (Fig. 1E, asterisk) and cells resembling those described in figure 1A (Fig. 1E, arrowheads), which lack the phenotype of constituent tissue cells.

\section{Effects of BMMC on injured nerve morphology}

Morphological evaluation was conducted on semi-thin (light microscopy, Fig. 2) and ultra-thin (electron microscopy, Fig. 3) sections of all tested nerves. As no significant differences were observed across contralateral nerves, proximal areas and naïve nerves at any of the DPI analyzed (Figs. 2A, 3A), assays focused on the crush and distal stumps (Figs. 2B, C; 3B, C).

\section{Histological and ultrastructural analysis}

Three DPI, the crush area of both nontreated and BMMC-treated rats showed fewer axons with an irregular structure, some of them smaller in size (Fig. 2B), indicating the beginning of a WD process with sharp axonal degeneration, fewer myelinated axons and the appearance of myelin debris (Fig. 3B).

Seven DPI, nontreated animals presented typical WD morphology, with large amounts of myelin and axon debris, while BMMC-treated animals showed a partial recovery in axon morphology and a significantly larger number of axons $(10.53 \pm 1.55$ vs. $37.48 \pm 3.79, \mathrm{p}<0.001)$. Fourteen DPI, non-treated rats still exhibited significantly fewer axons as compared to the BMMC-treated

group $(58.86 \pm 3.21$ vs $81.55 \pm 6.5, \mathrm{p}<0.01)$, the latter also presenting a higher degree of 
myelination. Finally, 21 DPI, the nontreated group showed the beginning of spontaneous remyelination, with the presence of small irregular axons, while BMMC-treated animals presented a remarkable recovery both in axon morphology and number (65.82 \pm 4.23 vs. 114.32 $\pm 6.44, \mathrm{p}<0.001)($ Fig. 2B, 3B).

Distal to the crush, both nontreated and BMMC-treated rats exhibited similar alterations in axon number and structure 3 DPI. Seven DPI, nontreated animals presented typical WD morphology, with large amounts of myelin and axon debris, while BMMC-treated rats showed a slight recovery in axon morphology. Fourteen DPI, nontreated animals also showed less recovery in axon morphology and number than the BMMC-treated group $(36.2 \pm 4.78$ vs $82.3 \pm 7.14$, $\mathrm{p}<0.001)$. And, $21 \mathrm{DPI}$, the nontreated group showed incipient remyelination with the appearance of scarcely myelinated axons, while BMMC-treated rats presented a substantial recovery in axon morphology and number (74.29 \pm 4.97 vs. $117.02 \pm 10.47$, p<0.001) (Fig. 2C, $3 C)$.

Regarding the evolution of axonal degeneration-regeneration within each experimental group, the number of axons in the crush area of non-treated rats fell sharply until 7 DPI and began to recover afterwards, though still failing to reach naïve values as late as 21 DPI. In contrast, BMMC-treated rats showed a milder reduction in the number of axons, with recovery beginning as early as $7 \mathrm{DPI}$ and full recovery at $21 \mathrm{DPI}$ (Fig. 4A, left panel). When comparing the distal area of nontreated and BMMC-treated rats, an abrupt decrease in axon number was observed in 
both groups until 7 DPI. However, compared to nontreated rats, BMMC-treated rats presented a much sharper recovery starting at 14 DPI and full recovery at 21 DPI (Fig. 4A, right panel).

A more specific analysis of highly myelinated axons (Fig. 4B) in the crush area rendered a smaller proportion in nontreated rats than BMMC-treated rats starting at 7 DPI $(47.22 \pm 13.1$ vs. $82.59 \pm 3.84)$ and onwards. In distal areas, a profound decrease in the percentage of highly myelinated axons was observed in both experimental groups, although slower in BMMC-treated rats and evident as from 7 DPI (7.037 \pm 4.05 vs. $48.53 \pm 8.28)$. G-ratio analysis confirmed that the axons found were myelinated (Fig. 4C).

\section{Immunohistochemical analysis}

MBP -the most sensitive protein in this experimental model ${ }^{30}$ - was used to show the evolution of the myelination process after injury. Comparisons between nontreated and BMMC-treated rats were made 7 and 14 DPI, 2 time points of clear degeneration. Immunohistochemical analyses revealed continuous MBP immunoreactivity (IR) in the contralateral nerves of both experimental groups. Seven DPI, loss of continuity and MBP reorganization in clusters in the proximal and distal areas was observed in nontreated rats, in contrast to a more continuous MBP-IR detected in BMMC-treated rats (Fig. 5A). Fourteen DPI, nontreated rats were still in the demyelination period but exhibited fewer clusters; in contrast, BMMC-treated rats showed barely any clusters and further improvement in MBP-IR along the ipsilateral nerve (Fig. 5B).

In support of the immunohistochemical results described above, Western Blot analyses revealed a decrease in MBP in the ipsilateral nerve of nontreated rats as compared to their contralateral 
nerve 7 DPI. In contrast, MBP levels in the ipsilateral and the contralateral nerve of BMMCtreated rats were virtually unaffected. Fourteen DPI, non-treated rats only showed a decrease in MBP content in the distal area of the ipsilateral nerve, while BMMC-treated rats again presented similar MBP levels both in the contralateral and the ipsilateral nerves (Fig. 5C).

Further support for BMMC effects on regeneration was obtained from immunohistochemical analyses using NF-h, $\mathrm{P}_{0}$ and p75 ${ }^{\mathrm{NTR}}$ (Fig. 6).

\section{Effects of BMMC on injured nerve functionality}

Electrophysiological analyses were conducted to determine whether histological improvements correlated with functional recovery in BMMC-treated animals. As no significant differences were observed between naïve and contralateral nerves at any of the survival times and groups analyzed, ipsilateral nerves were compared to naïve nerves. Figure 7 shows an increase in distal latency between 3 and 21 DPI in both nontreated and BMMC-treated rats, although complete recovery was only reached in the BMMC-treated group 60 DPI (Fig. 7A). On the other hand, a sharp decrease in CMAP amplitude was observed between 3 and 21 DPI in nontreated rats and between 3 and 7 DPI in BMMC-treated animals. However, BMMC-treated rats showed a substantial recovery in CMAP amplitude at $14 \mathrm{DPI}$, and both experimental groups exhibited almost complete recovery at 60 DPI (Fig. 7B). 


\section{Effects of BMMC on pain behavior after nerve injury}

Nontreated rats showed a considerable decrease in ipsilateral mechanical withdrawal threshold beginning 7 DPI and becoming most evident between 14 and 21 DPI. A progressive recovery was observed starting at $28 \mathrm{DPI}$, with mechanical withdrawal threshold reaching sham levels 35 , 42 and 49 DPI (Figure 8A). In contrast, mechanical withdrawal threshold in BMMC-treated rats virtually never changed, remaining comparable to sham rats throughout survival times analyzed (Figure 8A). Neither sham, nor nontreated or BMMC-treated rats exhibited changes in contralateral withdrawal threshold throughout the different survival times (Figure 8B).

Comparisons between nontreated and BMMC-treated rats showed statistically significant differences 14 and 21 DPI. Comparisons between sham and BMMC-treated rats only rendered statistically significant differences 14 DPI (Fig. 8A, B).

\section{DISCUSSION}

Within a model of WD, the present study proves the beneficial effects of systemically transplanted $\mathrm{BMMC}$ on regeneration and thus provides insights into a potentially therapeutic approach. Our experimental model encompasses 3 relevant features that may be important for functional nerve recovery, and may supersede previous studies using either the mononuclear ${ }^{14,37}$ or $\mathrm{MSC}^{38}$ fraction of bone marrow cells: first, immediate cell availability and acute intervention minimize time-dependent damage and even allow for autologous transplant (only 60 minutes between bone marrow isolation and BMMC injection) ${ }^{39,40}$; second, transplant of BMMC using the middle caudal artery constitutes a noninvasive $\operatorname{method}^{41}$; and, last but not least, the 
spontaneous migration of transplanted cells helps functional recovery. Such an approach also has the potential to lower costs and risk of contamination and reduce the need for Good Manufacturing Practice (GMP) facilities ${ }^{42}$, thus opening doors for new therapeutic strategies.

BMMC have recently become the focus of attention, not only because they are easily obtained, but also because they do not require culturing for expansion and/or differentiation. The heterogeneous population of BMMC is in line with the detectable configurations of cell memory disc (CMD) fluidity ${ }^{43}$. Positive aspects of BMMC transplantation also include cell death delay through transient trophic effects ${ }^{44,45}$ or effects associated to CMD theory ${ }^{43}$. Moreover, a synergic effect has been postulated for the stromal and non-stromal components of BMMC on regeneration, which indicates that BMMC may supersede the BMSC population in their regenerating ability ${ }^{46}$. Furthermore, our studies prove the potential of adult BMMC isolated right after injury, which prevents long term maintenance ${ }^{47}$ and the resulting uncertain effects, such as malignant transformation ${ }^{48}$, and enables autologous transplant, thus reducing collateral effects associated to allotransplant ${ }^{39}$.

Posttransplant images showing the presence of cells lacking a SC phenotype in the distal area confirm the arrival of transplanted cells. This selective migration to the injured nerve ${ }^{30}$ reinforces our hypothesis of an endogenous recruitment mechanism triggered by nerve injury and suggests the existence of a cross-talk between the injured nerve and the transplanted cells.

Flow cytometry analysis of living cells through CD45/SSC-H gate showed the classical 2 populations in the mononuclear fraction, $\mathrm{CD} 45^{\text {low }}$ associated with blast cells and $\mathrm{CD} 45^{\text {high }}$ related 
to lymphocytes and monocytes. The presence of contaminating granulocytes was singled out through CD45 ${ }^{\text {high }}$ expression and increased cellular complexity, whereas the erythroid precursors were identified through $\mathrm{CD}^{-} 5^{-}$expression and less cellular complexity. Under 20\% BMMC expressed pan-macrophage marker CD68 and myeloid lineage marker CD11b. The other population showing $\mathrm{CD} 45^{+} / \mathrm{CD} 68^{-} / \mathrm{CD} 11 \mathrm{~b}^{-} / \mathrm{CD}^{+}$and low granularity proved to reflect lymphoid lineage cells. A group of $\mathrm{CD} 45^{+} / \mathrm{CD} 105^{+}$cells with middle granularity was identified in the blast region, corresponding to the small proportion of MSC present in the BMMC fraction. Worth pointing out, Wistar rats have a different myeloid/lymphoid proportion (10:90) from other species like humans in peripheral blood ${ }^{49}$, which can be extrapolated to bone marrow or BMMC composition. This can explain the low expression levels observed in leukocyte markers CD68 and CD11b and the high abundance of lymphoid lineage cells.

After sciatic nerve crush, neutrophils are the first immune cells to infiltrate the distal area within $8 \mathrm{~h}$, but their presence is short-lived ${ }^{50}$. Within days, circulating monocytes are recruited and become dominant and responsible for complete degeneration ${ }^{51}$. Considering the composition of the transplanted cells (9\% granulocytes, $8 \%$ erythroid precursors and more than $60 \%$ mononuclear cells) and their regenerating ability after WD, it could be hypothesized that the small amount of remaining transplanted granulocytes will leave the lesion area within the first hours much like endogenous ones, which might thus confirm that the beneficial effect observed on sciatic nerve regeneration is explained by the mononuclear fraction. 
As regards BMMC effect on nerve repair, this manuscript shows that BMMC systemic transplant accelerates the onset of regeneration improving CMAP amplitude, which hints at the presence of regenerated axons. Besides, results from the present work show that a single systemic injection of BMMC completely prevents the decrease in mechanical withdrawal threshold compatible with mechanical hypersensitivity typically observed in rats with sciatic nerve $\operatorname{crush}^{52,53}$. In fact, BMMC-treated rats remained analgesic throughout the whole tested period, as compared to nontreated rats. Studies analyzing the analgesic role of BMMC are scarce; 1 of them, however, has shown that BMMC unilateral injections into the hind-limb skeletal muscle of rats with diabetic neuropathy ameliorate mechanical and cold hyperalgesia and improve vascular flow, motor and sensory conduction velocities of the affected nerves ${ }^{54,55}$.

Our results are also in line with a number of studies using BMSC to control chronic neuropathic pain induced by various injury models. Systemic injection of BMSC has been shown to reduce thermal and mechanical allodynia in rodents subjected to several types of nerve injury ${ }^{52,56,57 .}$ The ipsilateral intramuscular, intranganglionic and intrathecal administration of BMSC have also been proven effective ${ }^{56,58,59}$, with effects appearing to be long-lasting and equally efficient when BMSC are injected either at early or late stages of chronic constriction injury-induced neuropathic pain, at least with the intrathecal approach ${ }^{57}$. Finally, BMSC have also succeeded in reducing pain in patients with lumbar disc degeneration ${ }^{60}$ or osteoarthritis ${ }^{61}$.

The mechanisms involved in the analgesic action of systemic BMMC remain to be established. However, if evidence on BMSC homing in the lumbar spinal cord, neighboring lumbar dorsal 
root ganglion and the prefrontal cortex ${ }^{56,57,62}$ could be extrapolated to BMMC, paracrine actions at the site of nerve injury may be expected ${ }^{30}$. These actions against neuropathic pain may involve a reduction in the activation and proliferation of microglia and astrocytes, the suppression of excitatory synaptic transmission and an increase in action potential frequency ${ }^{57}$. To sum up, the prevention of neuropathic pain in BMMC-treated animals throughout periods of major behavioral challenge induced by nerve crush suggests that these cells are continually acting as analgesic agents.

A number of mechanisms have been proposed to explain BMMC beneficial effects once they have been recruited. Transdifferentiation to $\mathrm{SC}^{63}$, acceleration of debris removal ${ }^{64}$ and/or release of trophic and growth factors contributing to axonal growth and neuroprotection ${ }^{27,} 65$ have all been implicated. However, neuroimmunomodulation has more recently been postulated as a prevailing mechanism ${ }^{30,66,67}$. On the basis of recent evidence on the actions of BMSC, BMMC could be speculated to exert anti-inflammatory effects including the switching of proinflammatory to anti-inflammatory macrophages, a reduction in pro-inflammatory interleukins (IL) and the secretion of anti-inflammatory cytokines IL- $10^{55}$ and TGF- $\beta 1^{58}$, all currently under study in our lab.

To conclude, the beneficial role of BMMC in nerve injury exposed in the present work, through mechanisms yet to be established, suggests that these cells could be useful adjuvants to antiinflammatory/analgesic drug treatments in preventing their severe contralateral effects. 


\section{ACKNOWLEDGMENTS}

The authors thank Dr María Victoria Rosato-Siri, Dr Roberto Diez and Ms María Marta Rancez for their assistance in the elaboration of this manuscript, LANAIS-MLE for electron microscopy images and Mr. Guillermo Gastón for technical assistance. 


\section{REFERENCES}

1. Flores AJ, Lavernia CJ, Owens PW. Anatomy and physiology of peripheral nerve injury and repair. Am J Orthop 2000; 29: 167-173

2. Geuna, S, Raimondo S, Ronchi G, et al. Chapter 3: Histology of the peripheral nerve and changes occuring during nerve regeneration. Int Rev Neurobiol 2009; 87: 27-46

3. Dezawa M, Adachi-Usami E. Role of Schwann cells in retinal ganglion cell axon regeneration. Prog Retin Eye Res 2000; 19: 171-204

4. Mimura T, Dezawa M, Kanno H, Sawada H, Yamamoto I. Peripheral nerve regeneration by transplantation of bone marrow stromal cell-derived Schwann cells in adult rats. J Neurosurg 2004; 101: 806-812

5. Cameron SH, Alwakeel AJ, Goddard L, et al. Delayed post-treatment with bone marrowderived mesenchymal stem cells is neurorestorative of striatal medium-spiny projection neurons and improves motor function after neonatal rat hypoxia-ischemia. Molec and Cell Neurosc 2015; doi:10.1016/j.mcn.2015.03.019

6. Guerout N, Paviot A, Bon-Mardion N, et al. Co-transplantation of olfactory ensheathing cells from mucosa and bulb origin enhances functional recovery after peripheral nerve lesion. PLoS One 2011b; 6: e22816

7. Guerout N, Duclos C, Drouot L, et al. Transplantation of olfactory ensheathing cells promotes axonal regeneration and functional recovery of peripheral nerve lesion in rats. Muscle Nerve 2011a; 43: 543-551.

8. Chen CW, Corselli M, Péault B, Huard J. Human blood-vessel-derived stem cells for tissue repair and regeneration. J Biomed Biothechnol 2012; 597439 
9. Gu JH, Ji YH, Dhong ES, Kim DH, Yoon ES. Transplantation of Adipose Derived Stem Cells for Peripheral Nerve Regeneration in Sciatic Nerve Defects of the Rat. Curr Stem Cell Res Ther $2012 ; 7: 347-355$

10. Hsueh YY, Chang YJ, Huang TC, et al. Functional recoveries of sciatic nerve regeneration by combining chitosan-coated conduit and neurosphere cells induced from adipose-derived stem cells. Biomaterials 2014; 35: 2234-2244.

11. Plock JA, Schnider JT, Zhang W, et al. Adipose- and Bone Marrow-Derived Mesenchymal Stem Cells Prolong Graft Survival in Vascularized Composite Allotransplantation. Transplantation 2015; 99: 1765-1773

12. Sakai K, Yamamoto A, Matsubara K, et al. Human dental pulp-derived stem cells promote locomotor recovery after complete transection of the rat spinal cord by multiple neuroregenerative mechanisms. J Clin Invest 2012; 122: 80-90

13. Walsh SK, Kumar R, Grochmal JK, Kemp SW, Forden J, Midha R. Fate of stem cell transplants in peripheral nerves. Stem Cell Res 2012; 8: 226-238

14. Raheja A, Suri V, Suri A, et al. Dose-dependent facilitation of peripheral nerve regeneration by bone marrow-derived mononuclear cells: a randomized controlled study: laboratory investigation. J Neurosurg 2012; 117: 1170-1181

15. Tosta MML, Costa-Ferro ZS, Souza BS, et al. Early transplantation of bone marrow mononuclear cells promotes neuroprotection and modulation of inflammation after status epilepticus in mice by paracrine mechanisms. Neurochem Res 2014; 39: 259-68

16. Jones EA, Kinsey SE, English A, et al. Isolation and characterization of bone marrow multipotential mesenchymal progenitor cells. Arthritis Rheum. 2002; 46: 3349-60. 
17. Orkin SH. Diversification of haematopoietic stem cells to specific lineages. Nat Rev Genet 2000; $1: 57-64$

18. Weissman IL, Anderson DJ, Gage F. Stem and progenitor cells: origins, phenotypes, lineage commitments, and transdifferentiations. Annu Rev Cell Dev Biol 2001; 17: 387-403

19. Wang, QR, Wang BH, Huang YH, Dai G, Li WM, Yan Q. Purification and growth of endothelial progenitor cells from murine bone marrow mononuclear cells. J Cell Biochem 2008; 103: $21-29$

20. Kawamoto A, Losordo DW. Endothelial progenitor cells for cardiovascular regeneration. Trends Cardiovasc Med 2008; 18: 33-37

21. Yip HK, Chang LT, Chang WN, et al. Level and value of circulating endothelial progenitor cells in patients after acute ischemic stroke. Stroke 2008; 39: 69-74

22. Kienstra KA, Jackson KA, Hirschi KK. Injury mechanism dictates contribution of bone marrow-derived cells to murine hepatic vascular regeneration. Pediatr Res. 2008; 63:131-6

23. Chen $\mathrm{CH}$, Chang MY, Wang SS, Hsieh PC. Injection of autologous bone marrow cells in hyaluronan hydrogel improves cardiac performance after infarction in pigs. Am J Physiol Heart Circ Physiol. 2014; 306: H1078-86. doi: 10.1152

24. El-Mahdy N, Salem ML, El-Sayad M, El-Desouky KI, Zaghow N. Bone marrow mononuclear cells enhance anti-inflammatory effects of pravastatin against isoproterenolinduced myocardial infarction in rats. J Immunotoxicol 2015; 25:1-10

25. Nakano-Doi A, Nakagomi T, Fujikawa M, et al. Bone marrow mononuclear cells promote proliferation of endogenous neural stem cells through vascular niches after cerebral infarction. Stem Cells 2010; 28: 1292-1302 
26. Pimentel-Coelho PM, Mendez-Otero R. Cell therapy for neonatal hypoxic-ischemic encephalopathy. Stem Cells Dev 2010b; 19: 299-310

27. Zaverucha-Do-Valle C, Gubert F, Bargas-Rega M, et al. Bone marrow mononuclear cells increase retinal ganglion-cell survival and axon regeneration in the adult rat. Cell Transplant 2011; 20: 391-406

28. Ribeiro-Resende VT, Pimentel-Coelho PM, Mesentier-Louro LA, et al. Trophic activity derived from bone marrow mononuclear cells increases peripheral nerve regeneration by acting on both neuronal and glial cell populations. Neuroscience 2009; 159: 540-549

29. Setton-Avruj CP, Musolino PL, Salis C, et al. Presence of alpha-globin mRNA and migration of bone marrow cells after sciatic nerve injury suggests their participation in the degeneration/regeneration process. Exp Neurol 2007; 203: 568-578

30. Usach V, Goitia B, Lavalle L, Martinez Vivot R, Setton-Avruj P. Bone marrow mononuclear cells migrate to the demyelinated sciatic nerve and transdifferentiate into Schwann cells after nerve injury: attempt at a peripheral nervous system intrinsic repair mechanism. $J$ Neurosci Res 2011; 89: 1203-1217

31. Martinez-Vivot R, Goitia B, Usach V, Setton-Avruj CP. DMT1 as a candidate for nontransferrin-bound iron uptake in the peripheral nervous system. Biofactors 2013; 39: 476-484

32. Bradford MM. A rapid and sensitive method for the quantitation of microgram quantities of protein utilizing the principle of protein-dye binding. Anal Biochem.1976; 72: 248-54

33. Esperanza MA, Bollati F, Garcia-Keller C, et al. Stress-induced sensitization to cocaine: actin cytoskeleton remodeling within mesocorticolimbic nuclei. Eur J Neurosci. 2012; 36: 31033117 
34. Bennett GJ. Animal Models of Pain, in Methods in Pain Research, L. Kruger, Editor. CRC Press: Boca Raton, Florida.2001; p. 67-92

35. Brumovsky PR, Bergman E, Liu HX, Hökfelt T, Villar MJ. Effect of a graded single constriction of the rat sciatic nerve on pain behavior and expression of immunoreactive NPY and NPY Y1 receptor in DRG neurons and spinal cord. Brain Research 2004; 1006: 87-99.

36. Harrington AM, Olteanu H, Kroft SH. A dissociation of the CD45/Side Scatter "Blast gate". Am J Clin Pathol 2012;137:800-804

37. Kurwale NS, Suri V, Srivastava A, et al. Role of bone marrow derived pluripotent stem cells in peripheral nerve repair in adult rats: A morphometric evaluation. J Neurosci Rural Pract. $2015 ; 6: 152-159$

38. Yang HY1, Wu XM, Liu Y, He D. Transplantation of bone marrow mesenchymal stem cells promotes learning and memory functional recovery and reduces hippocampal damage in rats with alcohol-associated dementia. Transplantation 2015; 99: 492499

39. Naito Y, Rocco K, Kurobe H, Maxfield M, Breuer C, Shinoka T. Tissue engineering in the vasculature. Anat. Rec. 2014; 297: 83-97.

40. Yao M, Zhou Y, Xue C, et al. Repair of Rat Sciatic Nerve Defects by Using Allogeneic Bone Marrow Mononuclear Cells Combined With Chitosan/Silk Fibroin Scaffold. Cell Transplant 2016; 25: 983-989

41. Taguchi A, Sakai C, Soma T, et al. Intravenous Autologous Bone Marrow Mononuclear Cell Transplantation for Stroke: Phase1/2a Clinical Trial in a Homogeneous Group of Stroke Patients. Stem Cell Dev 2015; 24: 2207-2218 
42. Giannini S, Buda R, Vannini F, Cavallo M, Grigolo B. One-step bone marrow-derived cell transplantation in talar osteochondral lesions. Clin Orthop Relat Res 2009; 467: 3307-3320

43. Anjamrooz SH. CDM kinetics and regenerative medice. Am J Transl Res 2016; 8:1615-1624

44. Borlongan CV, Lind JG, Dillon-Carter O, et al. Bone marrow grafts restore cerebral blood flow and blood brain barrier in stroke rats. Brain Res 2004; 1010: 108-116

45. Muñoz JR, Stoutenger BR, Robinson AP, Spees JL, Prockop DJ. Human stem/progenitor cells from bone marrow promote neurogenesis of endogenous neural stem cells in the hippocampus of mice. Proc Natl Acad Sci USA 2005; 102: 18171-18176

46. Song F, Tang J, Geng R, et al. Comparison of the efficacy of bone marrow mononuclear cells and bone mesenchymal stem cells in the treatment of osteoarthritis in a sheep model. Int. J. Clin. Exp. Pathol 2013; 7: 1415-1426

47 Wu KH1, Chan CK, Tsai C, et al. Effective treatment of severe steroid-resistant acute graftversus-host disease with umbilical cord-derived mesenchymal stem cells. Transplantation 2011; 91: $1412-1416$

48. Røsland GV, Svendsen A, Torsvik A, et al. Long-term cultures of bone marrow-derived human mesenchymal stem cells frequently undergo spontaneous malignant transformation. Cancer Res 2009; 69: 5351-5359

49. Arcila Quiceno VH, Conde Cotes CA, Nieto Pico JE, Garcia Prada FH. Comparison of hematology reference values of strain wistar/UIS (Rattus norvergicus) with parameters established in standards laboratories. Spei Domus 2010; 12:45-51

50. Perkins NM, Tracey DJ. Hyperalgesia due to nerve injury: role of neutrophils. Neuroscience $2000 ; 101: 745-757$ 
51. DeFrancesco-Lisowitz A, Lindborg JA, Niemi JP, Zigmond RE. The neuroimmunology of degeneration and regeneration in the peripheral nervous system. Neuroscience 2015; 302:174203.

52. Coronel MF, Hernando-Insúa A, Rodriguez JM, et al. Oligonucleotide IMT504 reduces neuropathic pain after peripheral nerve injury. Neurosci Lett 2008; 444: 69-73.

53. Vogelaar CF, Vrinten DH, Hoekman MF, Brakkee JH, Burbach JP, Hamers FP. Sciatic nerve regeneration in mice and rats: recovery of sensory innervation is followed by a slowly retreating neuropathic pain-like syndrome. Brain Res. 2004; 1027: 67-72.

54. Naruse K, Sato J, Funakubo M, et al. Transplantation of bone marrow-derived mononuclear cells improves mechanical hyperalgesia, cold allodynia and nerve function in diabetic neuropathy. PLoS One 2011; 6: e27458.

55. Anjamrooz SH. Cell memory-based therapy. J Cell Mol Med. 2015; 9:2682-9. doi: 10.1111/jcmm.12646.

56. Guo W, Wang H, Zou S, et al. Bone marrow stromal cells produce long-term pain relief in rat models of persistent pain. Stem Cells 2011; 29: 1294-303.

57. Siniscalco D, Giordano C, Galderisi U, et al. Long-lasting effects of human mesenchymal stem cell systemic administration on pain-like behaviors, cellular, and biomolecular modifications in neuropathic mice. Front Integr Neurosci 2011; 5: 79.

58. Chen G, Park CK, Xie RG, Ji RR. Intrathecal bone marrow stromal cells inhibit neuropathic pain via TGF-beta secretion. J Clin Invest 2015; 125: 3226-40.

59. Musolino PL, Coronel MF, Hökfelt T, Villar MJ. Bone marrow stromal cells induce changes in pain behavior after sciatic nerve constriction. Neurosci Lett.2007; 418: 97-101. 
60. Orozco L, Soler R, Marera C, Alberca M, Sanchez A, Garcia-Sancho J. Intervertebral disc repair by autologous mesenchymal bone marrow cells: a pilot study. Transplantation 2011; $97: 822-828$

61. Vega A, Martin-Ferrero MA, Del Canto F, et al. Treatment of knee osteoarthritis with allogenic bone marrow mesenchymal stem cell: a randomized controlled trial. Transplantation 2015; 99: 1681-1690

62. Coronel MF, Musolino PL, Villar MJ. Selective migration and engraftment of bone marrow mesenchymal stem cells in rat lumbar dorsal root ganglia after sciatic nerve constriction. Neurosci Lett 2006; 405: 5-9.

63. Zhang S, Wang D, Estrov Z, Raj S, Willerson JT,. Yeh ET. Both cell fusion and transdifferentiation account for the transformation of human peripheral blood CD34-positive cells into cardiomyocytes in vivo. Circulation 2004; 110: 3803-7.

64. Yin Y, Cui Q, Li Y, et al. Macrophage-derived factors stimulate optic nerve regeneration. $J$ Neurosci 2003; 23: 2284-2293

65. Barbosa da Fonseca LM, Battistella V, de Freitas GR, et al. Early tissue distribution of bone marrow mononuclear cells after intra-arterial delivery in a patient with chronic stroke. Circulation 2009; 120: 539-541

66. Garg S, Wang W, Prabath BG, et al. Bone marrow transplantation helps restore the intestinal mucosal barrier after total body irradiation in mice. Radiation Research 2014; 181: 229-239.

67. Prockop DJ. "Stemness" does not explain the repair of many tissues by mesenchymal stem/multipotent stromal cells (MSCs). Clin Pharmacol Ther 2007; 82: 241-243 


\section{FIGURE LEGENDS}

Fig. 1: Morphological $(n=3)$ and biochemical $(n=6)$ characterization of BMMC. A1-3: electron microscopy photomicrographs of freshly isolated BMMC (12000X, scale bar: $0.4 \mu \mathrm{m})$.

B: RT-PCR products run in 1\% agarose gel for detection of multipotent cell markers CD34 (B1), CD90 (B2) and SC marker S100ß (B3), visualized with Sybr Safe. Reactions without template cDNA were run as negative controls. In all cases, from left to right: marker, negative control and independent BMMC samples. C: flow cytometry analysis of BMMC; dot plot showing different subpopulations and their proportions, A: granulocytes, B: erythroid precursors, C: blasts, D: lymphocytes, E: monocytes (C1); histogram of CD45 expression (purple) and autofluorescense of cells (light blue) (C2); histogram of multipotent markers CD34 and CD90 and mesenchymal stem cell marker CD105; SC markers S100ß, p75NTR and MBP (C3); dot plot of CD3, CD68 and CD11b expression (C4). Quantification of cells positive for each marker using FlowJ software (C5). D: Cells dyed with cell tracker orange CMTMR (red) and Hoechst (blue) (D1); analysis of BMMC-CMTMR migration in a naïve nerve and the distal area of the ipsilateral nerve of nontreated and BMMC-treated animals (D2). E: Semi-thin section images of a naïve nerve and the distal area of the ipsilateral nerve of nontreated and BMMC-treated rats 3 DPI. Asterisks indicate myelin and axon debris, arrowhead indicates a BMM-like cell (40X, scale bar: $20 \mu \mathrm{m})$.

Fig. 2: Analysis of semi-thin sections of axonal bundles in nontreated and BMMC-treated animals at different survival times $(\mathbf{n}=\mathbf{3}, \mathbf{4 0 X})$. Semi thin sections of $\mathbf{A}$ : naïve and contralateral nerves and proximal stump of the ipsilateral nerve. B: crush area of nontreated and BMMC-treated animals. C: distal area of nontreated and BMMC-treated animals. Scale bar: 20 
$\mu \mathrm{m}$. Arrows indicate intact axons; arrowheads indicate irregular axons; asterisks indicate myelin and axon debris

Fig. 3: Ultra-structural analysis of sciatic nerves from nontreated and BMMC-treated animals at different survival times $(\mathbf{n}=\mathbf{3}, \mathbf{3 0 0 0 X})$. Electron microscopy images of $\mathbf{A}$ : naïve and contralateral nerves and proximal stump of the ipsilateral nerve. B: crush area of non-treated and BMMC-treated animals. C: distal area of non-treated and BMMC-treated animals. Scale bar: 2 $\mu \mathrm{m}$. Arrows indicate intact axons; arrowheads indicate irregular axons; asterisks indicate myelin and axon debris

Fig. 4: Axon quantification in nontreated and BMMC-treated animals at different survival times $(\mathbf{n = 3})$. A: percentage of axons in naïve nerves and the crush (left panel) and distal (right panel) areas in both experimental groups as a function of survival time. B: percentage of highly myelinated axons in naïve nerves and in the crush (left panel) and distal (right panel) areas in both experimental groups as a function of survival time. C: G-ratio of naïve nerves and crush and distal areas of the ipsilateral nerve of nontreated and BMMC-treated animals.

Values expressed as the mean \pm SEM. Statistical analysis performed through ANOVA followed by Dunnett's test or by t-test analysis; in all cases $*^{*} \mathrm{p}<0.05, * * \mathrm{p}<0.01, * * * \mathrm{p}<0.001$ (each experimental group vs. naïve rats) and $\# \mathrm{p}<0.05, \# \# \mathrm{p}<0.01$, \#\#\#p<0.001 (comparison between experimental groups). 
Fig. 5: Immunohistochemical and Western Blot detection of MBP in nontreated and BMMC-treated animals at different survival times $(n=5,60 X)$. A, B: Fluorescence photomicrographs of sections of Contralateral nerves, and proximal and distal areas of ipsilateral nerves after incubation with MBP antiserum (in red) and Höechst (in blue, for detection of nuclei) at 7 and 14 DPI. Scale bar: $30 \mu \mathrm{m}$. C: Western blot analysis (magnified for image clarity), Coomassie blue-colored PVDF membrane and quantification of MBP 7 DPI (left panel) and 14 DPI (right panel). MW=molecular weight markers; $\mathrm{C}=$ contralateral nerve; $\mathrm{P}=$ proximal area; $\mathrm{D}=$ distal area. Values expressed as the mean \pm SEM. Statistical analysis performed through ANOVA followed by Tukey's test; ${ }^{*} \mathrm{p}<0.05 ; * * \mathrm{p}<0.01, * * * \mathrm{p}<0.001$.

Fig. 6: Immunohistochemical detection of NF-h, $P_{0}$ and p75NTR in nontreated and BMMC-treated animals at different survival times $(n=5,60 X)$. A, B and C: Fluorescence photomicrographs of sections of contralateral and distal areas of ipsilateral nerves after incubation with conditioned media for NF-h, antibodies anti- $\mathrm{P}_{0}$ and anti-p75NTR (red) and Höechst (blue, for detection of nuclei) at 7 and 14 DPI. Scale bar: $30 \mu \mathrm{m}$

Fig. 7: Analysis of the distal latency and amplitude of the CMAP in naïve, non-treated and BMMC-treated rats at different survival times $(\mathbf{n}=6)$. A: Distal latency of naïve and ipsilateral nerves in nontreated and BMMC-treated animals. B: Amplitude of CMAP of naïve and ipsilateral nerves in nontreated and BMMC-treated animals. Values expressed as the mean \pm SEM. Statistical analysis performed through ANOVA followed by Dunnett's test or by t-test analysis; in all cases $* \mathrm{p}<0.05, * * \mathrm{p}<0.01, * * * \mathrm{p}<0.001$ (each experimental group vs. naïve rats) and $\# \mathrm{p}<0.05, \# \# \mathrm{p}<0.01, \# \# \mathrm{p}<0.001$ (comparison between experimental groups). 
Fig. 8: Analysis of mechanical withdrawal threshold in sham, nontreated and BMMCtreated rats at different survival times $(\mathbf{n = 1 1})$. A: Values are expressed as median \pm median absolute deviation. Statistical analysis performed through Kruskal-Wallis Rank Sum Test followed by Dunn's multiple comparison post hoc test; $* \mathrm{p}<0.05 ; * * \mathrm{p}<0.01$ (nontreated rats vs. sham) and \#\# p<0.01 (nontreated vs. BMMC-treated rats). B: Table showing the comparison between contralateral and ipsilateral paws of sham, nontreated or BMMC-treated rats between 1 and 49 DPI. Values expressed as the mean \pm SEM. Statistical analysis performed using the Wilcoxon matched pairs test; significant differences indicated in bold $* p<0.05 ; * * p<0.01$. 


\section{Figure 1}
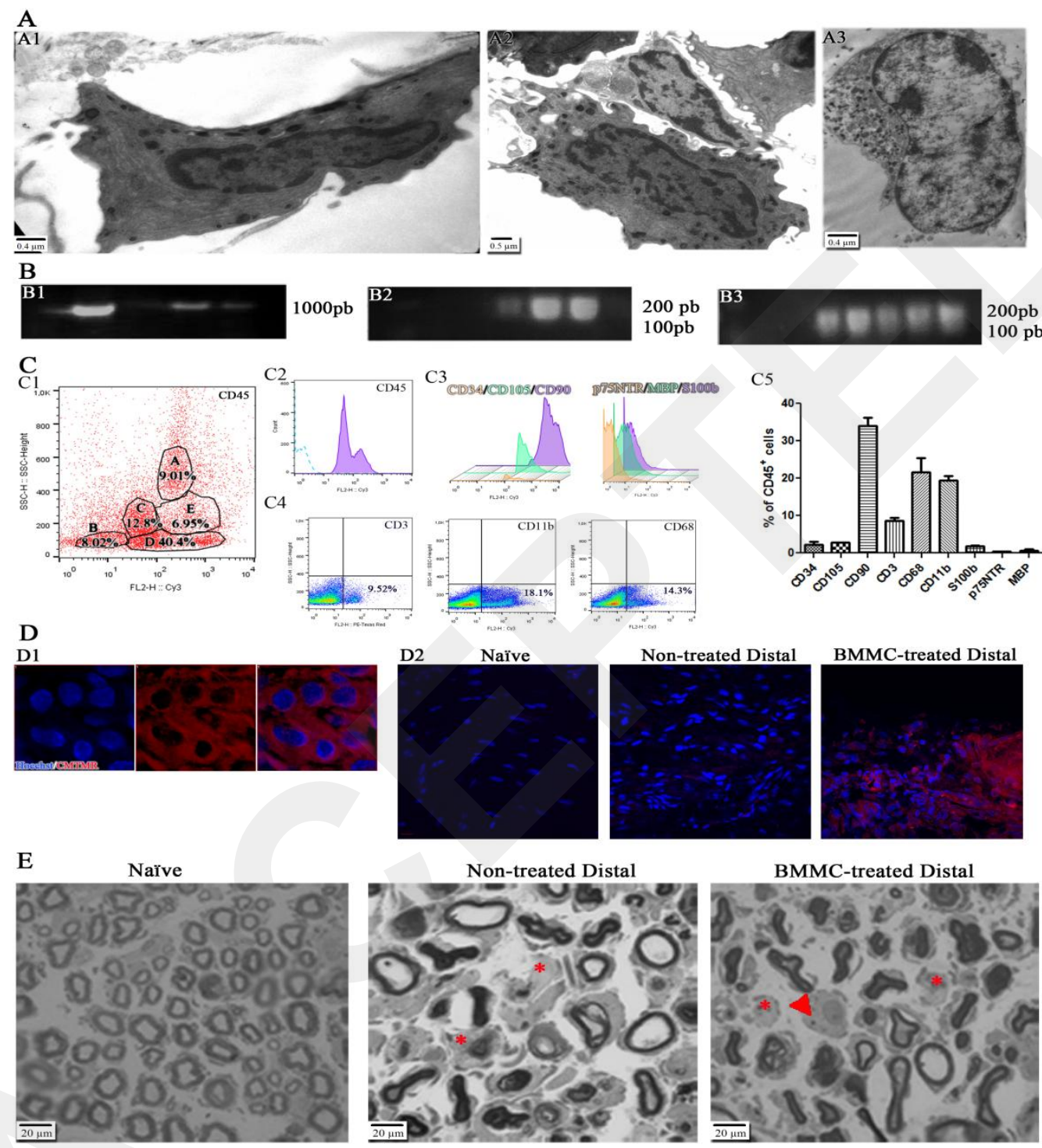

BMMC-treated Distal

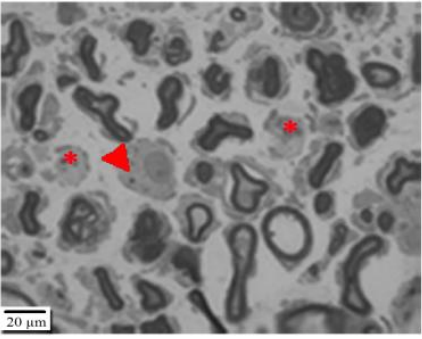




\section{Figure 2}

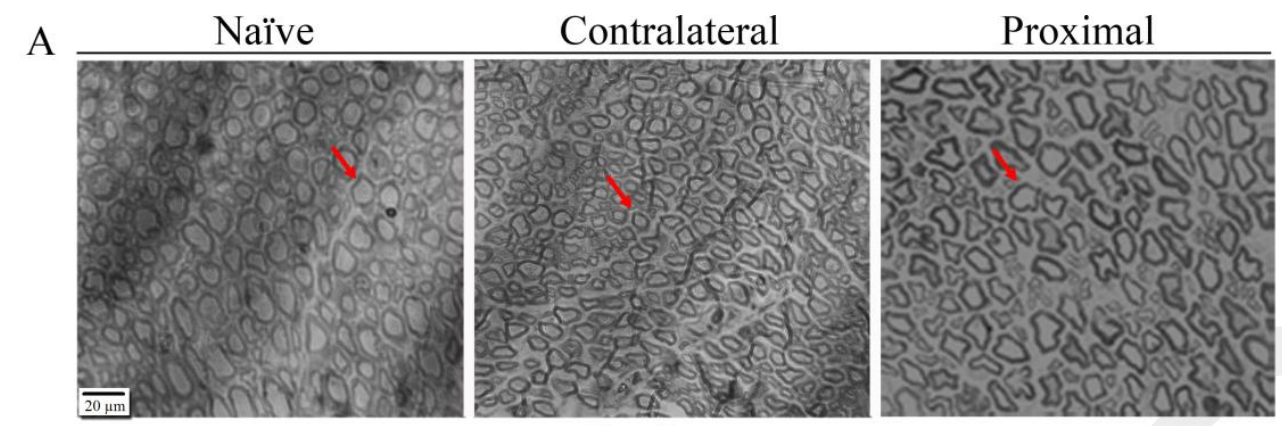

B

Crush area
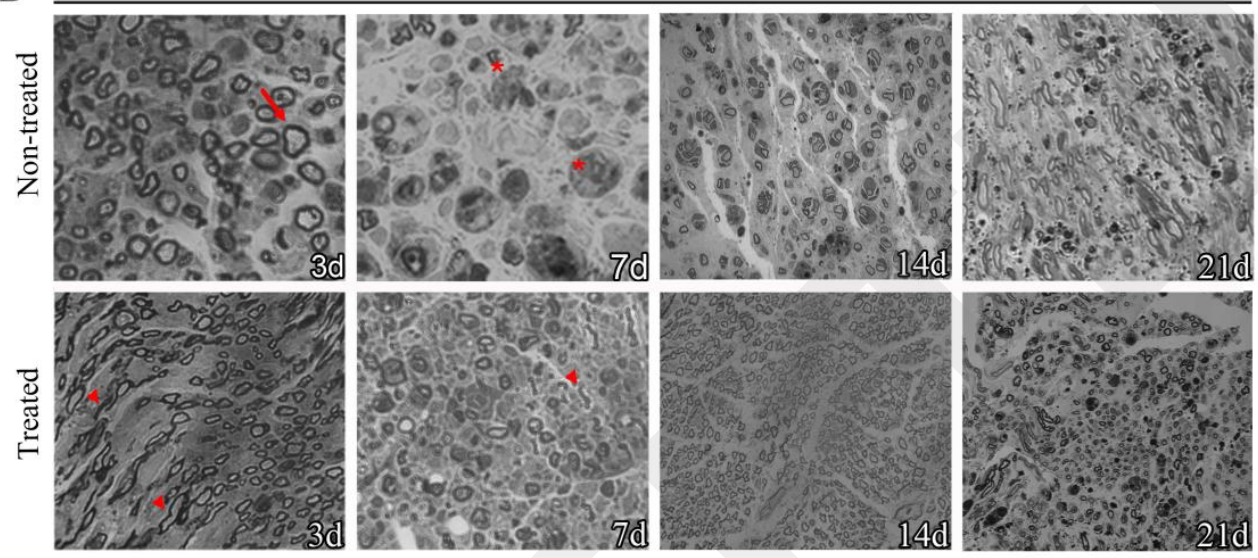

$\mathrm{C}$

\section{Distal area}

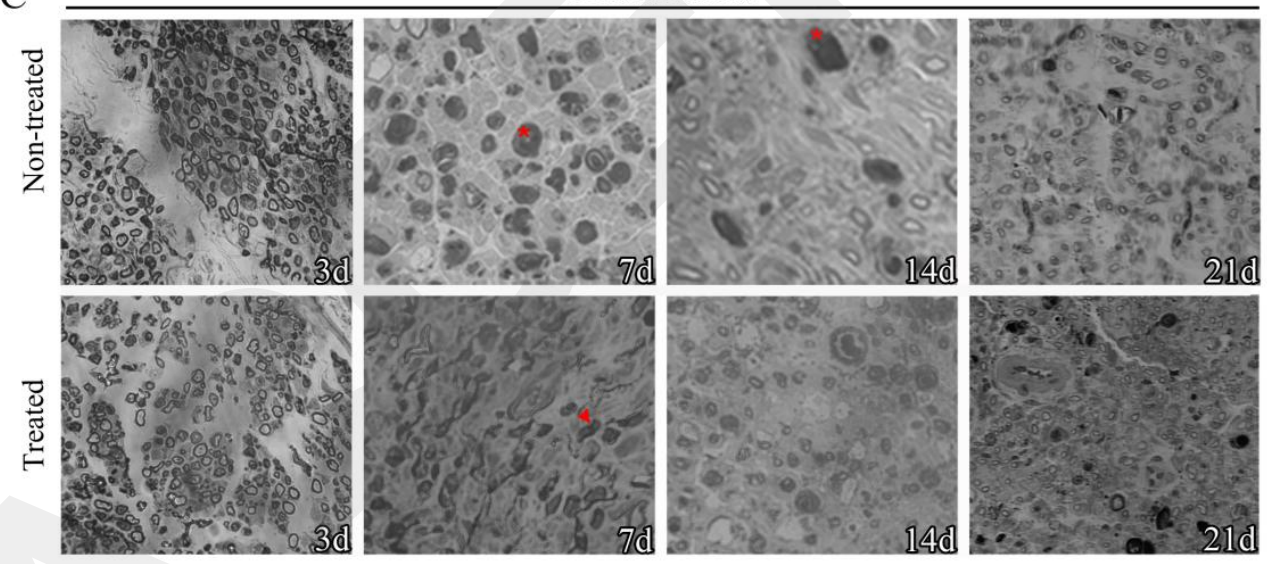


Figure 3
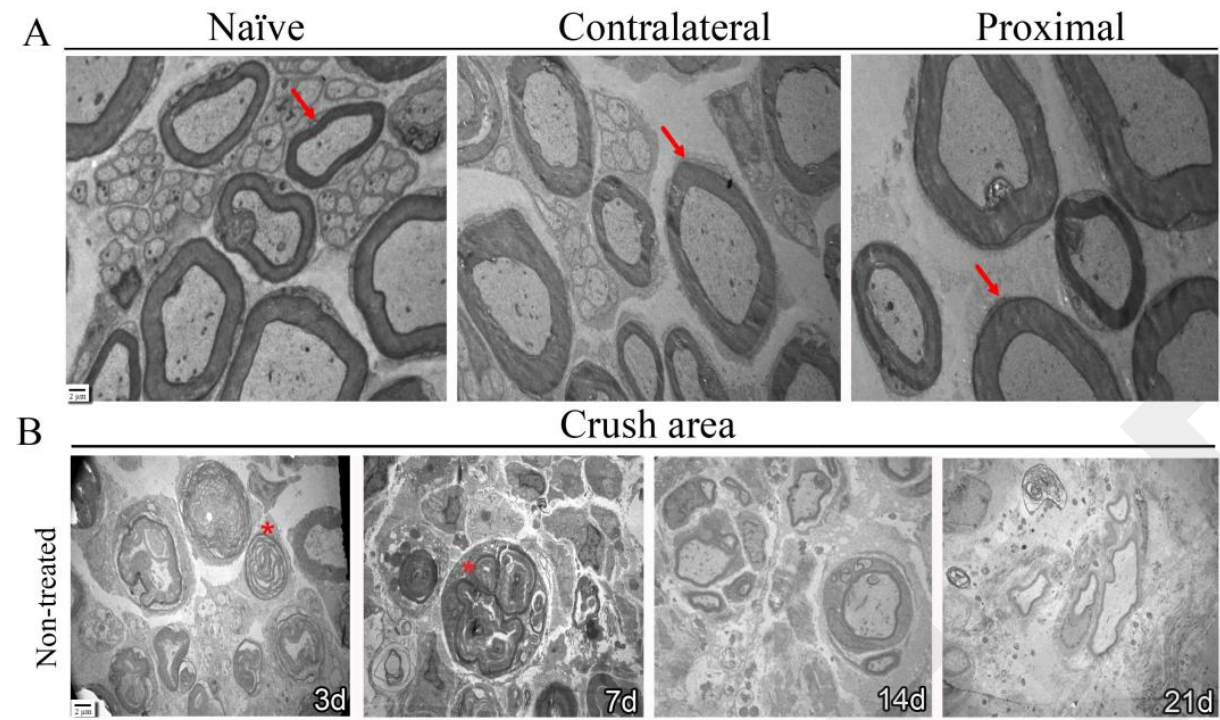

Crush area
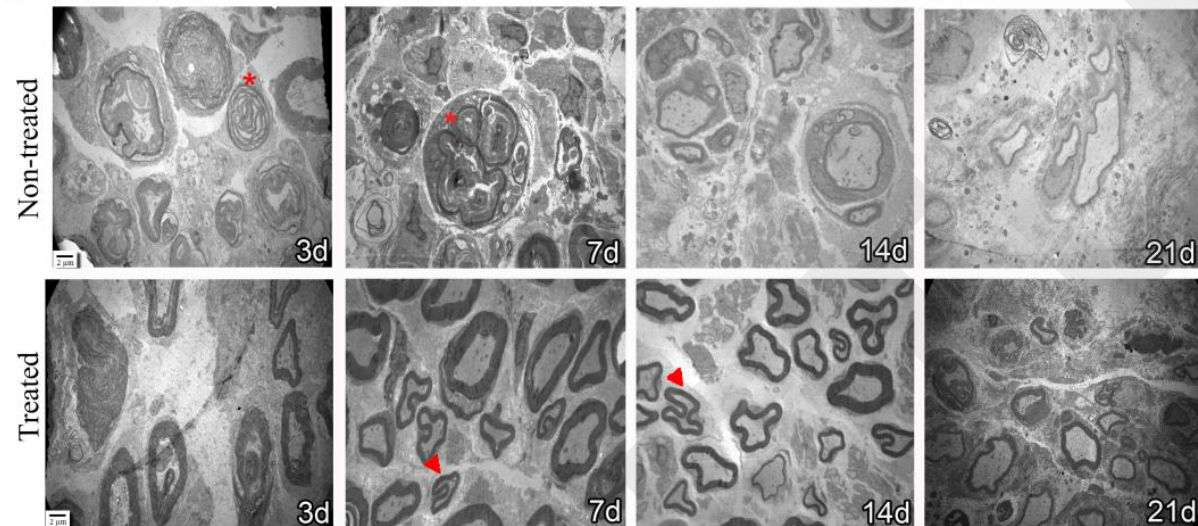

$\mathrm{C}$
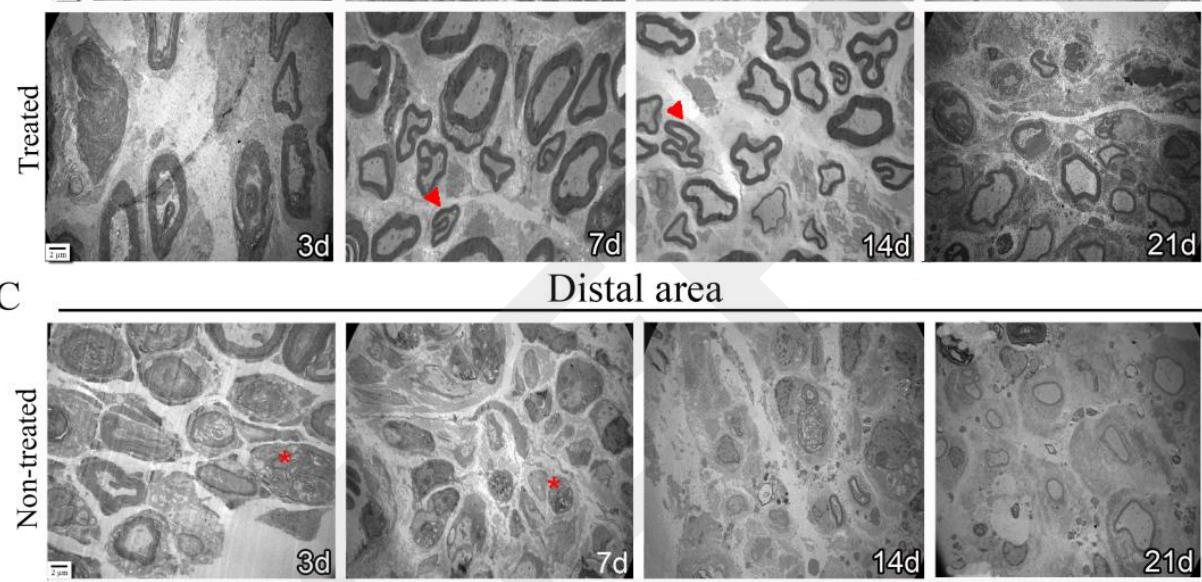

Distal area
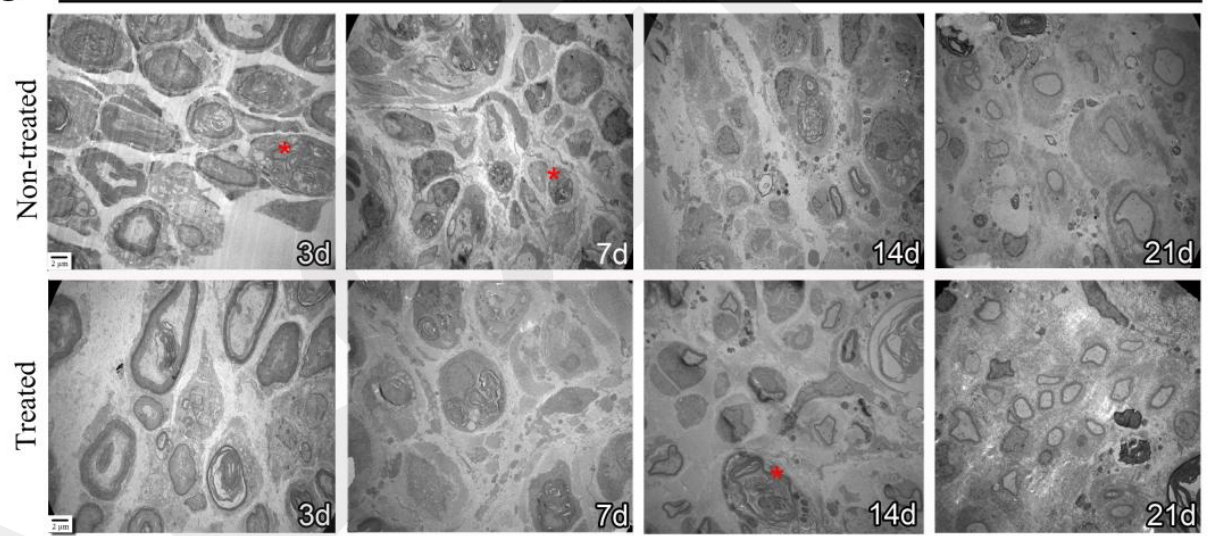


\section{Figure 4}

A

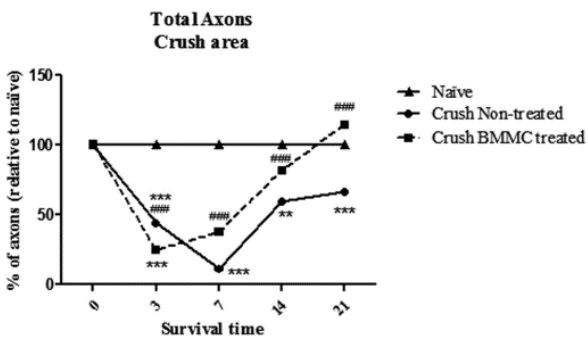

B

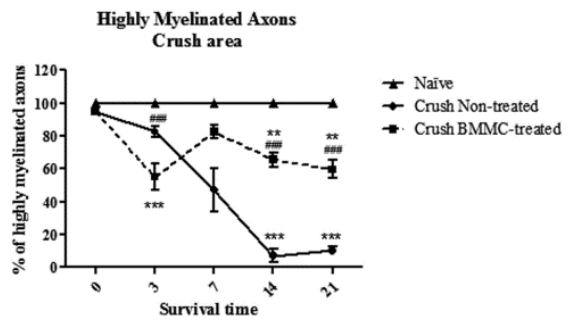

Total Axons

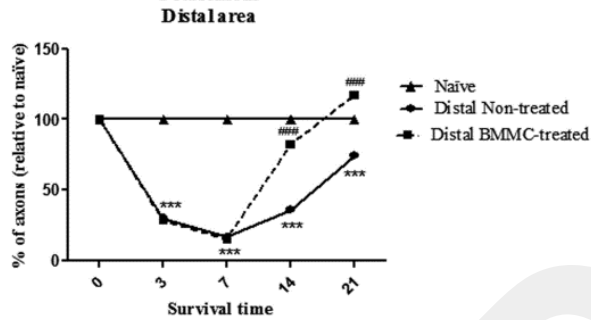

Highly Myelinated Axons Distal area

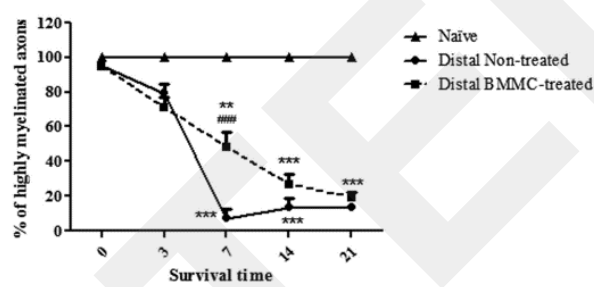

c

\begin{tabular}{|c|c|c|c|c|c|c|c|c|c|}
\hline & \multicolumn{3}{|c|}{3 days } & \multicolumn{2}{|c|}{7 days } & \multicolumn{2}{|c|}{14 days } & \multicolumn{2}{|c|}{21 days } \\
\hline g-ratio & Naïve & Crush & Distal & Crush & Distal & Crush & Distal & Crush & Distal \\
\hline $\begin{array}{l}\text { Non- } \\
\text { treated }\end{array}$ & $0.69 \pm 0.01$ & $\begin{array}{c}0.81 \pm 0.04 \\
* *\end{array}$ & $\begin{array}{c}0.7 \pm 0.01 \\
\#\end{array}$ & $0.75 \pm 0.06$ & $\begin{array}{c}0.93 \pm 0.03 \\
* * *\end{array}$ & $\begin{array}{c}0.8 \pm 0.01 \\
* * *\end{array}$ & $\begin{array}{c}0.89 \pm 0.005 \\
* * *\end{array}$ & $\begin{array}{c}0.8 \pm 0.01 \\
* * *\end{array}$ & $\begin{array}{c}0.82 \pm 0.01 \\
* * *\end{array}$ \\
\hline $\begin{array}{l}\text { BMMC- } \\
\text { treated }\end{array}$ & & $\begin{array}{c}0.90 \pm 0.02 \\
* * *\end{array}$ & $\begin{array}{c}0.81 \pm 0.02 \\
* * *\end{array}$ & $0.62 \pm 0.03$ & $\begin{array}{c}0.65 \pm 0.05 \\
\#\end{array}$ & $\begin{array}{c}0.67 \pm 0.01 \\
\# \# \#\end{array}$ & $\begin{array}{c}0.69 \pm 0.06 \\
\# \#\end{array}$ & $\begin{array}{c}0.72 \pm 0.01 \\
\# \# \#\end{array}$ & $\begin{array}{c}0.74 \pm 0.01 \\
\# \# \#\end{array}$ \\
\hline
\end{tabular}


Figure 5

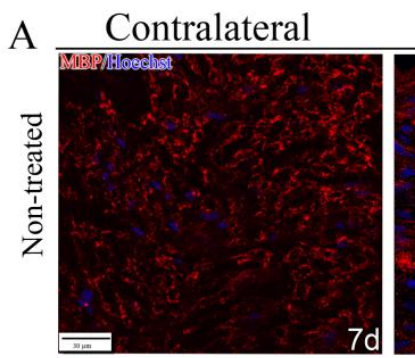

Proximal

Distal

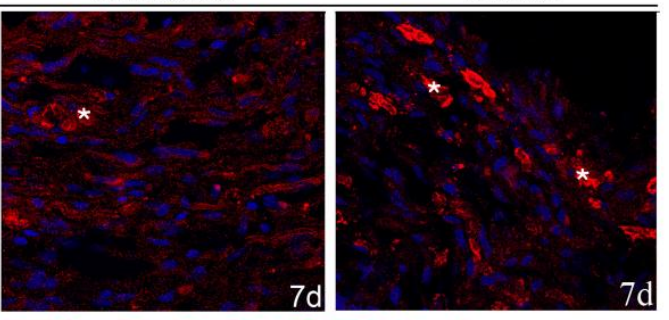

莺
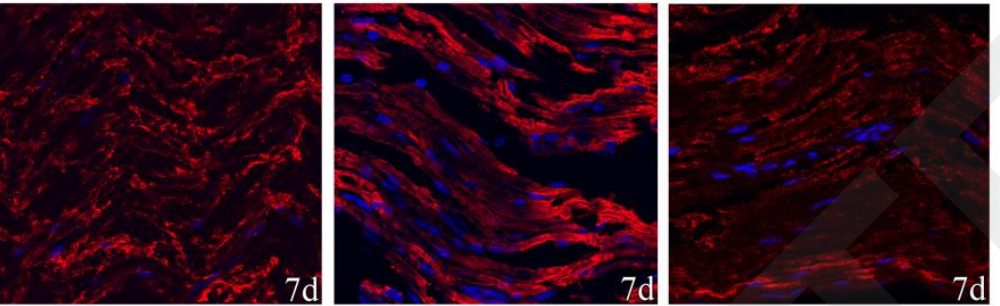

B Contralateral

Proximal

Distal

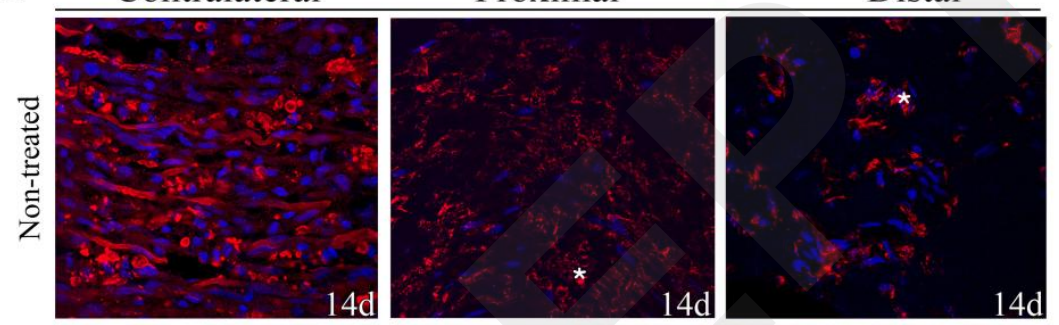

苂
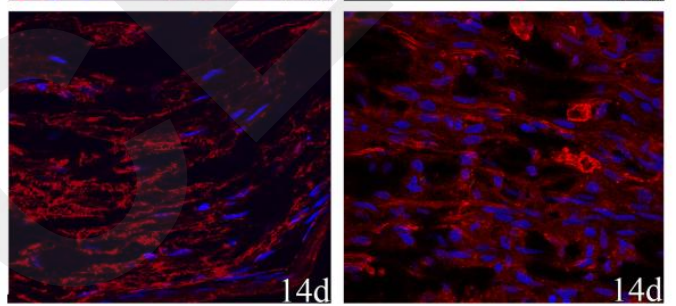

C

MBP 7 days post-injury

MBP 14 days post-injury
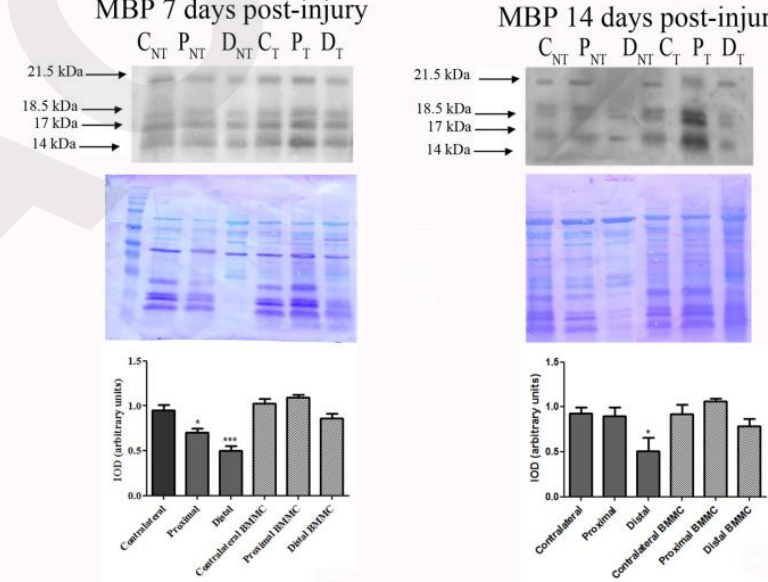
Figure 6

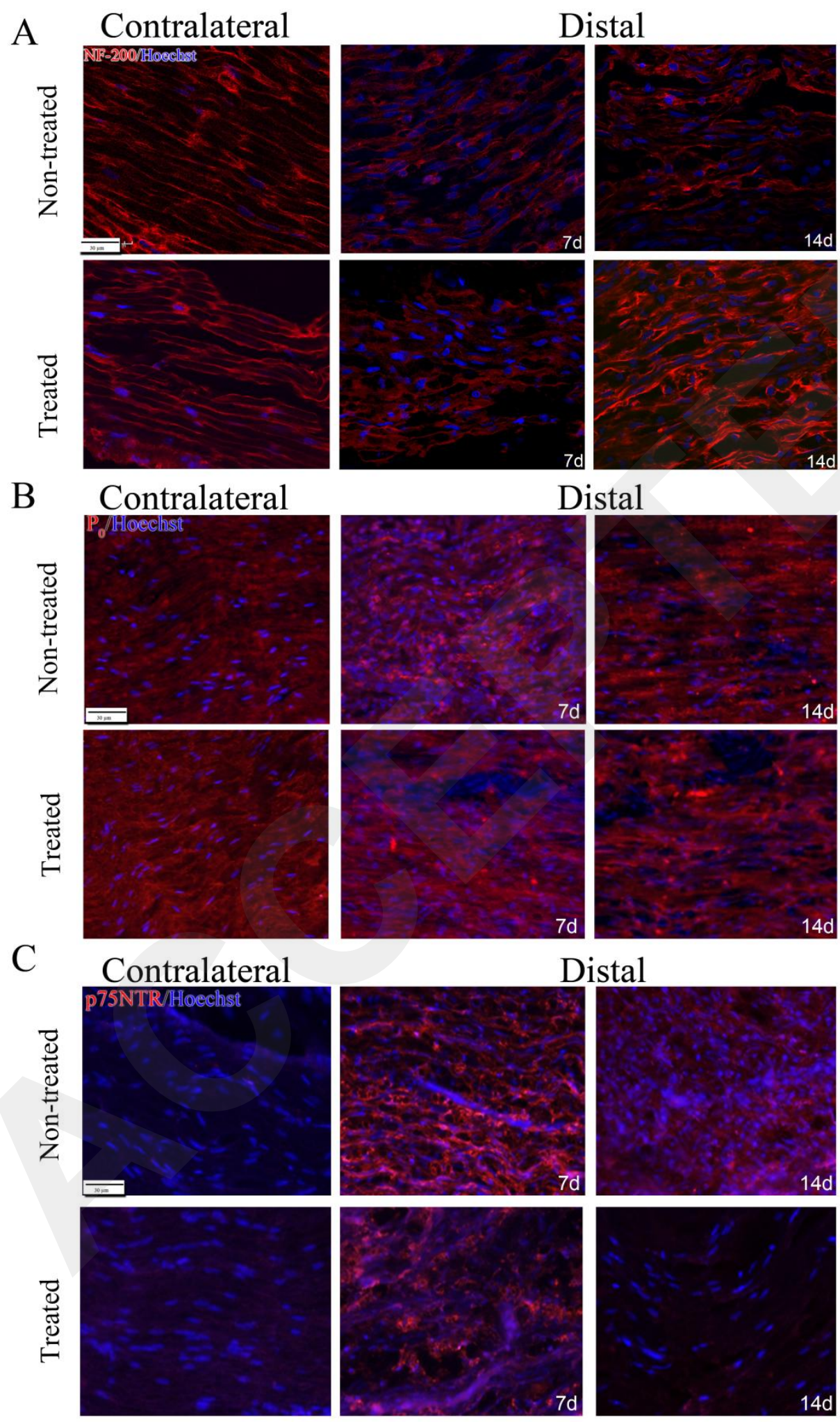


Figure 7
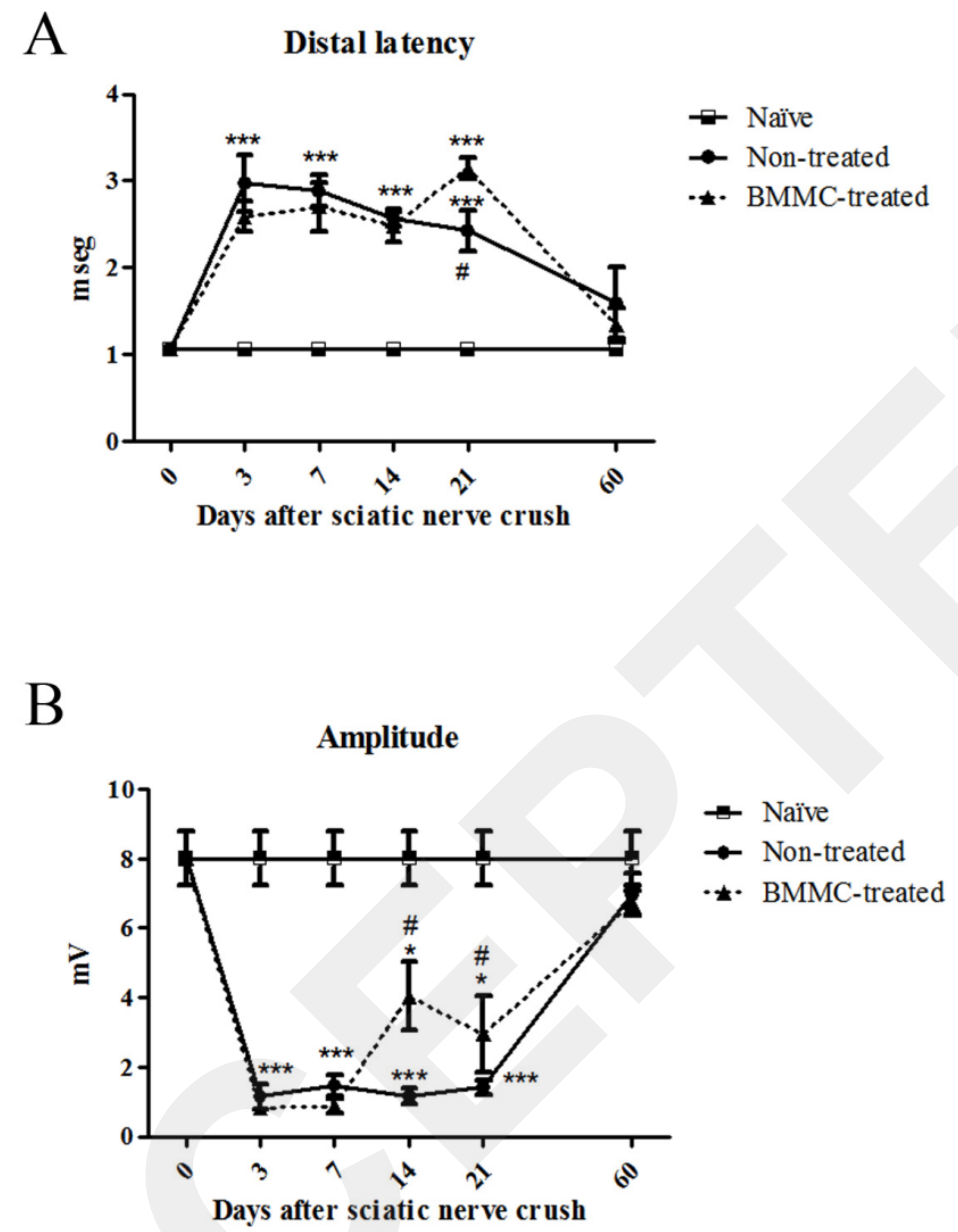


\section{Figure 8}

A

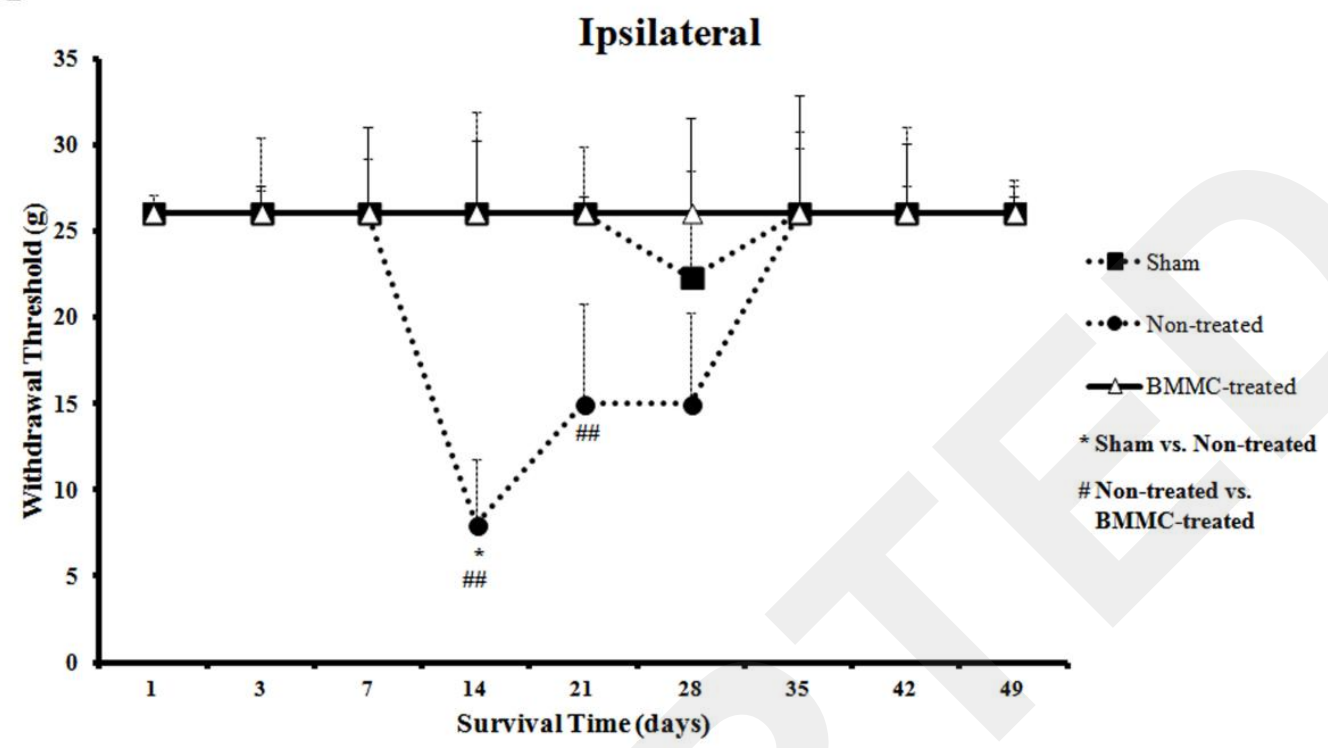

$\mathrm{B}$

\begin{tabular}{c|cccccc} 
& \multicolumn{2}{|c}{ Sham } & \multicolumn{2}{c}{ Non-treated } & \multicolumn{2}{c}{ BMMC-treated } \\
\hline Day & Contralateral & Ipsilateral & Contralateral & Ipsilateral & Contralateral & Ipsilateral \\
\hline $\mathbf{1}$ & 26 & 26 & 26 & $26 \pm 1.13$ & 26 & 26 \\
$\mathbf{3}$ & 26 & $26 \pm 1.38$ & $26 \pm 1$ & $26 \pm 4.4$ & $26 \pm 1.27$ & $26 \pm 1.64$ \\
$\mathbf{7}$ & $26 \pm 1.38$ & $26 \pm 3.16$ & $26 \pm 1$ & $26 \pm 5.02$ & 26 & $26 \pm 5$ \\
$\mathbf{1 4}$ & $26 \pm 2.64$ & $26 \pm 5.86$ & $\mathbf{2 6} \pm \mathbf{1 . 1 6}$ & $\mathbf{8} \pm \mathbf{3 . 8 2}$ & $26 \pm 1.16$ & $26 \pm 4.25$ \\
$\mathbf{2 1}$ & 26 & $26 \pm 3.9$ & $\mathbf{2 6} \pm \mathbf{3 . 1 9}$ & $\mathbf{1 5} \pm \mathbf{5 . 8 2}$ & $26 \pm 1$ & $26 \pm 1$ \\
$\mathbf{2 8}$ & $26 \pm 1.45$ & $22.3 \pm 6.22$ & $\mathbf{2 6} \pm \mathbf{2}$ & $\mathbf{1 5} \pm \mathbf{5 . 2 5}$ & $26 \pm 1.52$ & $26 \pm 5.55$ \\
$\mathbf{3 5}$ & 26 & $26 \pm 4.74$ & $26 \pm 3$ & $26 \pm 3.82$ & $26 \pm 2$ & $26 \pm 6.82$ \\
$\mathbf{4 2}$ & $26 \pm 1.56$ & $26 \pm 1.63$ & $26 \pm 1.28$ & $26 \pm 5.06$ & $26 \pm 0.67$ & $26 \pm 4.09$ \\
$\mathbf{4 9}$ & $26 \pm 4.87$ & $26 \pm 1.63$ & 26 & $26 \pm 2$ & 26 & $26 \pm 1$
\end{tabular}




\section{TABLE}

\begin{tabular}{|c|c|c|c|}
\hline Gene & & Sequence & Temp $\left({ }^{\circ} \mathrm{C}\right)$ \\
\hline \multirow[t]{2}{*}{ S100及 } & $\mathrm{F}$ & 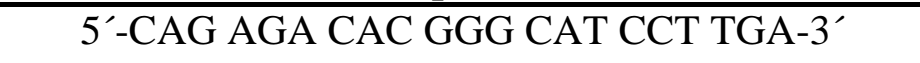 & 64 \\
\hline & $\mathrm{R}$ & 5'-GGG ATT AAG AGA GGG TCT GCT-3' & \\
\hline \multirow[t]{2}{*}{ CD90 } & $\mathrm{F}$ & 5'-GCC TGA CCC GAG AGA AGA AGA AG-3' & 60 \\
\hline & $\mathrm{R}$ & 5'-TGG TGG TGA AGT TGG CTA GAG TAA G-3' & \\
\hline \multirow[t]{2}{*}{ CD34 } & $\mathrm{F}$ & 5'-ATG CCG GTC CAC AGG GGC-3' & 60 \\
\hline & $\mathrm{R}$ & 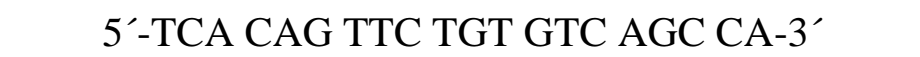 & \\
\hline \multirow[t]{2}{*}{ GFAP } & $\mathrm{F}$ & $5^{\prime}$-GAT GGA GCG GAG ACG T-3' & 55 \\
\hline & $\mathrm{R}$ & 5'-ACA CTG TAT GGC AAG GGC-3' & \\
\hline \multirow[t]{2}{*}{ p75NTR } & $\mathrm{F}$ & 5'-CCT GCC TGG ACA ATG TTA CA-3' & 55 \\
\hline & $\mathrm{R}$ & 5'-GCC AAG ATG GAG CAA TAG AC-3' & \\
\hline \multirow[t]{2}{*}{$\mathbf{P}_{\mathbf{0}}$} & $\mathrm{F}$ & 5'-TCT TTT ACC TGG CGC TAC CAG-3' & 60 \\
\hline & $\mathrm{R}$ & 5'-GTT GAC CCT TGG CAT AGT GCA-3' & \\
\hline \multirow[t]{2}{*}{ MBP } & $\mathrm{F}$ & 5'-CAGAGACACGGGCATCCTTGA-3' & 58 \\
\hline & $\mathrm{R}$ & 5'-GGGATTAAGAGAGGGTCTGCT-3' & \\
\hline
\end{tabular}

Table 1: Primer sequences. Forward and reverse sequences of primers used for RT-PCR studies. 